\title{
Meta-Analysis
}

\section{Comparing Pain Reduction Following Vertebroplasty and Conservative Treatment for Osteoporotic Vertebral Compression Fractures: A Meta-Analysis of Randomized Controlled Trials}

\author{
Jintao Liu, MD, PhD², Xiaofeng Li, MD, PhD², Dezhi Tang, MD, PhD², Xuejun Cui, MD, PhD², \\ Xiaochun Li, MD1', Min Yao, MD², Penfei Yu, MD1', Xiang Qian, MD', \\ Yongjun Wang, $\mathrm{MD}, \mathrm{PhD}^{2}$, and Hong Jiang $\mathrm{MD}, \mathrm{PhD}^{1}$
}

From: ${ }^{1}$ Department of Orthopedic Surgery, Suzhou Hospital of Traditional Chinese Medicine, Suzhou, Jiangsu 215009, China Institute of Spine, Shanghai University of Traditional Chinese Medicine, Shanghai 200032, China

Drs Liu, Li, Yu, Qian and Jiang, Department of Orthopedic

Surgery, Suzhou Hospital of Traditional Chinese Medicine, Suzhou, Jiangsu 215009, China

Drs Li, Tang, Cui, Yao and Wang, Institute of Spine, Shanghai University of Traditional Chinese Medicine, Shanghai 200032, China

Address Correspondence: Hong Jiang, MD, PhD Chairman \& Professor, Department of Orthopedic Surgery,

Suzhou Hospital of Traditional Chinese Medicine,

889 Wuzhongxi Road, Suzhou, Jiangsu 215009, China

E-mail: doctorhong@yeah.net

Disclaimer: Jintao Liu and Xiaofeng $\mathrm{Li}$ contributed equally to this article. This study was supported by the Natural Science Fundation of China (81102604)

Conflict of interest: Each author certifies that he or she, or member of his or her immediate family, has no commercial association, (i.e., consultancies, stock ownership, equity interest, patent/licensing arrangements, etc.) that might post a conflict of interest in connection with the submitted manuscript.

Manuscript received: 12-07-2012 Revised manuscript received: o1-20-2013 Accepted for publication: 02-08-2013

Free full manuscript: www.painphysicianjournal.com
Background: Osteoporotic vertebral compression fractures (OVCFs) are the most common osteoporotic fractures. Pain is the main symptom. Percutaneous vertebroplasty (PVP) is a therapeutic procedure performed to reduce pain in vertebral compression fractures. Numerous case series and several small, non-blinded, non-randomized controlled studies have suggested that vertebroplasty is an effective means of relieving pain from osteoporotic fractures. However, a recent pooled analysis from 2 multicenter randomized controlled trials concluded that the improvement in pain afforded by PVP was similar to placebo.

Objective: To compare the amount of pain reduction measured using the visual analog scale when OVCF is treated with vertebroplasty or conservatively, and assess the clinical utility of PVP.

Design: A meta-analysis and systematic review of randomized controlled trials was performed comparing pain reduction following vertebroplasty and conservative treatment.

Limitations: There were few data sources from which to extract abstracted data or published studies. There were only 5 randomized controlled trials that met our criteria. The conservative treatments used as comparators in these trials were different.

Methods: A search of MEDLINE from January 1980 to July 2012 using PubMed, the Cochrane Database of Systematic Reviews and Controlled Trials, CINAHL, and EMBASE. Relevant reports were examined by 2 independent reviewers and the references from these reports were searched for additional trials, using the criteria established in the QUOROM statement.

Results: Pooled results from 5 randomized controlled trials are shown. There was no difference in pain relief in the PVP group at 2 weeks and one month when compared with the conservatively managed group. Pain relief in the PVP group was greater than that of the conservative group at 3 months, 6 months, and 12 months. However, after subgroup analysis, pain scores were similar between the PVP group and the sham injection group from 2 weeks to 6 months. Compared with non-operative therapy, PVP reduced pain at all times studied.

Conclusion: PVP has some value for relieving pain; however, the possibility of a placebo effect should be considered. PVP has gained acceptance as a complementary treatment when conservative management has failed before its benefits have been fully understood. More large scale, double blinded, controlled trials are necessary in order to quantify the pain relief afforded by PVP more precisely.

Key words: Vertebroplasty, osteoporosis, vertebral compression fracture, randomized controlled trials, systemic review, meta-analysis

Pain Physician 2013; 16:455-464 


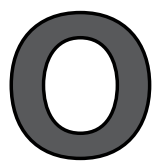

steoporotic vertebral compression fractures (OVCF) are a common cause of pain and disability and are associated with increased mortality (1). Patients with vertebral fractures can present with severe back pain lasting for weeks or months. Until recently, the mainstays of treatment were conservative: bed rest, analgesia, immobilization, and then physical therapy (2). Vertebroplasty, a procedure in which bone cement is injected percutaneously into the fractured vertebral body, was developed as an alternative option for the treatment of pain (3-5). Percutaneous vertebroplasty (PVP) is generally seen as a safe and effective procedure for painful OVCF (69). However, there is a body of opinion that the longterm analgesic effect of PVP for the treatment of acute and subacute fractures is not superior to conservative treatment, and that PVP should be only be offered to patients after conservative treatment has failed (10-12). The benefits compared with conservative treatment have not been evaluated until now.

The aim of this study was to compare the analgesic effects of PVP with conservative treatment of OVCF in a meta-analysis of randomized controlled trials. To achieve the aim we performed this systematic review. We searched a large quantity of relevant references and selected several publications in accordance with our requirements. Then we utilized the RevMan Version 5.0.2 software (The Cochrane Collaboration, England) to assess the risk of bias and finally determined 5 references for the meta-analysis. The subgroup analysis at various follow-up times was also performed.

\section{Methods}

\section{Selection Criteria}

All peer reviewed randomized controlled trials published in English up to July 2012 that compared vertebroplasty with conservative or sham treatments for OVCF and used the visual analog scale (VAS) as an objective measure of pain were identified and reviewed. Although there are many measures of pain, such as VAS, Numeric Rating Scale (NRS), McGill Pain Questionnaire (MPQ), Chronic Pain Grade Scale (CPGS), et al, most of publications use the VAS as an objective measure of pain. In order to unify the selection criteria, we chose the VAS as an objective measure of pain in this study.

\section{Search Strategy}

Two independent reviewers conducted a comput- erized search of MEDLINE using PubMed, the Cochrane Database of Systematic reviews, the Cochrane Central Register of Controlled Trials, CINAHL, and EMBASE to find relevant articles published between January 1980 and July 2012. The search terms used were "vertebroplasty AND compression fracture AND randomized control trial."

\section{Quality Assessment}

Articles which met the selection criteria were assessed the quality using Review Manager (RevMan) software and the bias was determined using the Cochrane Risk of Bias table. The Cochrane Risk of Bias table includes 7 bias: random sequence generation (selection bias), allocation concealment (selection bias), blinding of participants and personnel (performance bias), blinding of outcome assessment (detection bias), incomplete outcome data (attrition bias), selective reporting (reporting bias), and other bias. Articles which were in accordance with 3 or more bias had high quality $(13,14)$. We finally selected these articles with high quality for the meta-analysis.

\section{Analysis Technique}

Data analysis wasconducted using RevMan Version 5.0.2 software provided by the Cochrane Collaboration. All analyses were carried out on an intention-to-treat basis; that is, all patients randomly assigned to a treatment group were included in the analyses according to the assigned treatment, irrespective of whether they received the treatment or were excluded from analysis by the investigators. For categorical variables, weighted risk ratios and their $95 \%$ confidence intervals $(\mathrm{Cl})$ were calculated using RevMan 5.0.2 software according to the Peto method. Results were tested for heterogeneity at a significance level of $P<0.05$ according to the methods outlined. A fixed effects model was used if there was no evidence of heterogeneity between studies; if there was evidence of heterogeneity, a random effects model was used for the meta-analysis.

For trials reporting change from baseline values (15), the mean and standard deviation (SD) of final values was obtained by using the following formula (16), the correlation between baseline and final values $(r$ baseline, final $)$ was assumed to be $0.5: \mathrm{SD}^{2}$ change $=\mathrm{SD}_{\text {baseline }}{ }^{+}$ $S D_{\text {final }}^{2}-2 r_{\text {baseline, final }} S D_{\text {baseline }} S D_{\text {final }}$.

\section{Results}

The literature search initially yielded 1,766 relevant trials from PubMed, the Cochrane Database of 
Systematic reviews, the Cochrane Central Register of Controlled Trials, CINAHL, and EMBASE. Searching the inclusion criteria in title and abstract, we achieved 10 articles $(3,12,15,17-23)$, and selected 6 articles by excluding 4 articles, among them, 3 articles were nonrandomized controlled trials (21-23) and one article was about percutaneous kyphoplasty (20).

The trial assessors selected 6 randomized controlled trials for further quality analysis and review $(3,12,15,17$ 19). However, the study reported by Voormolen et al (19) was excluded as patients were allowed to cross over from the conservative group to the PVP group after 2 weeks of treatment and there was deemed to have been a high risk of bias. Thus 5 randomized controlled trials were used in the meta-analysis. The study selection process and reasons for exclusion are summarized in Fig. 1.

The 5 randomized controlled trials selected represented a total of 291 patients undergoing vertebroplasty and 286 patients managed conservatively. A list of the studies accepted for the meta-analysis is provided in Table 1. When the PVP groups are compared with

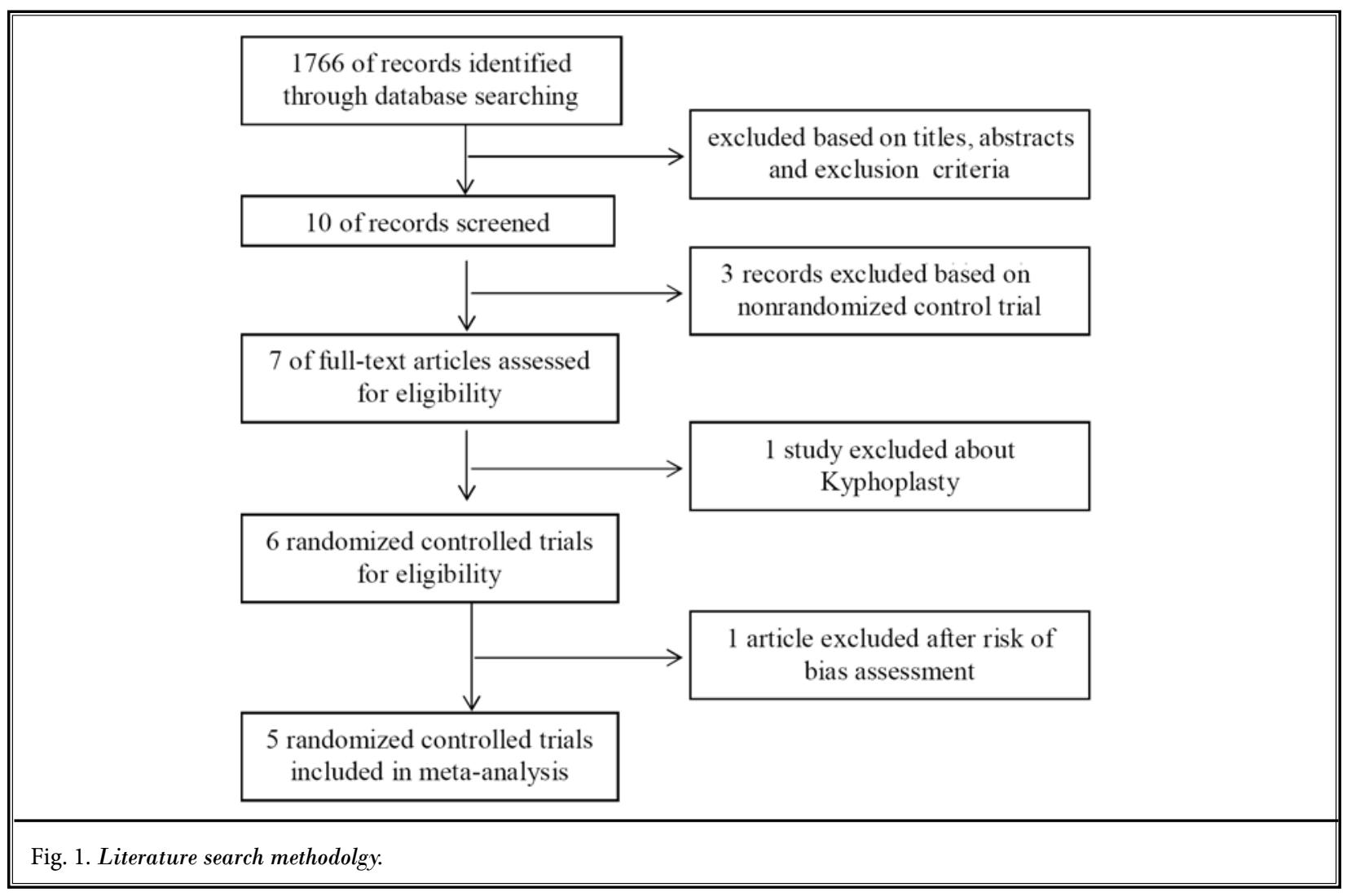

Table 1. Details of the studies included in the meta-analysis

\begin{tabular}{|l|c|c|c|c|c|}
\hline \multicolumn{7}{|c|}{ Study Characteristics } \\
\hline & Control & Sample size (PVP/Control) & Female & PVP (Age) & Control (Age) \\
\hline Buchbinder, 2009 & placebo & $78(38 / 40)$ & 62 & $74.2 \pm 14.0$ & $78.9 \pm 9.5$ \\
\hline Klazen, 2010 & OPT & $202(101 / 101)$ & 140 & $75.2 \pm 9.8$ & $75.4 \pm 8.4$ \\
\hline Farrokhi, 2011 & OMT & $82(40 / 42)$ & 60 & $72(59-90)$ & $74(55-87)$ \\
\hline Kallmes, 2009 & placebo & $131(68 / 63)$ & 99 & $73.4 \pm 9.4$ & $74.3 \pm 9.6$ \\
\hline Rousing, 2009 & CT & $50(26 / 24)$ & 40 & $80(76.9,83.3)$ & $80(77.6,82.6)$ \\
\hline
\end{tabular}

PVP: percutaneous vertebroplasty; OPT: optimum pain treatment; OMT: optimal medical therapy; CT: conservative treatment 
the conservative treatment groups; no statistically significant differences in age or gender proportion were found (Table 1). The pain VAS data reported in each study are presented in Table 2.

Two reviewers independently assessed the methodological quality of the included trials with Review Manager software, assessing factors such as randomization, allocation concealment, whether baseline data were similar, blinding, blinding of outcome assessments, and selective reporting. The outcome is summarized in Fig. 2. There was a low risk of selection bias given the use of computerized random number generators and opaque sealed envelopes in all studies.

There were no differences in pain relief between the PVP and the conservative groups at 2 weeks and one month $(P=0.14$ and 0.08 respectively, Figs. 3-4); however, PVP appeared to afford greater long-term pain relief at 2-3 months, 6 months, and 12 months $(P<$ 0.0001 , Figs. 5-7). A degree of heterogeneity was noted among the pain scores reported at different times. In a subgroup analysis, we divided the conservative group into a sham injection group $(15,18)$ and a non-operative group $(3,12,17)$. We found no difference in pain scores between the PVP and the sham injection groups at 2 weeks, one month, 3 months, or 6 months $(P=0.65$, $0.18,0.63$, and 1, respectively, Figs. 3-6). However, compared with non-operative therapy, the reduction in pain afforded by PVP was significantly greater than that of the non-operative group at 2 weeks, one month, 3 months, 6 months, and 12 months $(P<0.0001$, Figs. $3-7)$.

\section{Discussion}

Our meta-analysis showed that there was no difference in pain relief between the PVP and the conservatively managed groups at 2 weeks and one month. Pain relief in the PVP group was superior to that of the conservative group at 3 months, 6 months, and 12 months. Pain scores were similar between the PVP and sham injection groups from 2 weeks to 6 months. When compared with non-operative therapy, PVP reduced pain at all times at which it was measured.

There were differences between the PVP group and the conservative group at different time points, which may be a consequence of the variety of conserva-

Table 2. Visual analog pain scales (VAS) reported in the studies included in the meta-analysis

\begin{tabular}{|c|c|c|c|c|c|c|c|c|c|c|c|}
\hline & & \multicolumn{2}{|c|}{ Buchbinder 2009} & \multicolumn{2}{|c|}{ Klazen 2010} & \multicolumn{2}{|c|}{ Farrokhi 2011} & \multicolumn{2}{|c|}{ Rousing 2009} & \multicolumn{2}{|c|}{ Kallmes 2009} \\
\hline & & PVP & Control & PVP & Control & PVP & Control & PVP & Control & PVP & Control \\
\hline \multirow{2}{*}{ Preop } & VAS & $7.4 \pm 2.1$ & $7.1 \pm 2.3$ & $7.8 \pm 1.5$ & $7.5 \pm 1.6$ & $8.4 \pm 1.6$ & $7.2 \pm 1.7$ & $7.5(6.6,8.4)$ & $8.8(8.2,9.3)$ & $6.9 \pm 2.0$ & $7.2 \pm 1.8$ \\
\hline & $\mathrm{N}$ & 38 & 40 & 101 & 101 & 40 & 42 & 19 & 17 & 68 & 63 \\
\hline \multirow{2}{*}{$1 \mathrm{w}$} & VAS & $1.5 \pm 2.5$ & $2.1 \pm 2.8$ & $3.5 \pm 2.5$ & $5.6 \pm 2.5$ & $3.3 \pm 1.5$ & $6.4 \pm 2.1$ & & & & \\
\hline & $\mathrm{N}$ & 37 & 37 & 97 & 93 & 40 & 42 & & & & \\
\hline \multirow{2}{*}{$2 \mathrm{w}$} & VAS & & & & & & & & & $4.3 \pm 2.9$ & $4.5 \pm 2.8$ \\
\hline & $\mathrm{N}$ & & & & & & & & & 68 & 63 \\
\hline \multirow{2}{*}{$1 \mathrm{~m}$} & VAS & $2.3 \pm 2.6$ & $1.7 \pm 3.3$ & $2.5 \pm 2.5$ & $4.9 \pm 2.6$ & & & & & $3.9 \pm 2.9$ & $4.6 \pm 3.0$ \\
\hline & $\mathrm{N}$ & 35 & 38 & 96 & 92 & & & & & 67 & 61 \\
\hline \multirow{2}{*}{$2 \mathrm{~m}$} & VAS & & & & & $3.2 \pm 2.2$ & $6.1 \pm 2.1$ & & & & \\
\hline & $\mathrm{N}$ & & & & & 40 & 42 & & & & \\
\hline \multirow{2}{*}{$3 \mathrm{~m}$} & VAS & $2.6 \pm 2.9$ & $1.9 \pm 3.3$ & $2.5 \pm 2.7$ & $3.9 \pm 2.8$ & & & $1.8(0.8,2.8)$ & $2.6(1.2,4.0)$ & & \\
\hline & $\mathrm{N}$ & 36 & 37 & 92 & 86 & & & 23 & 17 & & \\
\hline \multirow{2}{*}{$6 \mathrm{~m}$} & VAS & $2.4 \pm 3.3$ & $2.1 \pm 3.3$ & $2.3 \pm 2.7$ & $3.9 \pm 2.9$ & $2.2 \pm 2.1$ & $4.1 \pm 1.5$ & & & & \\
\hline & $\mathrm{N}$ & 35 & 36 & 89 & 81 & 40 & 42 & & & & \\
\hline \multirow{2}{*}{$12 \mathrm{~m}$} & VAS & & & $2.2 \pm 2.7$ & $3.8 \pm 2.8$ & $2.2 \pm 2.1$ & $4.1 \pm 1.8$ & & & & \\
\hline & $\mathrm{N}$ & & & 86 & 77 & 38 & 39 & & & & \\
\hline Notes & VAS & \multicolumn{2}{|c|}{ Change Mean \pm SD } & \multicolumn{2}{|c|}{ Mean \pm SD } & \multicolumn{2}{|c|}{ Mean \pm SD } & \multicolumn{2}{|c|}{ Mean $(\mathrm{cl})$} & \multicolumn{2}{|c|}{ Mean \pm SD } \\
\hline
\end{tabular}


tive treatments employed in the selected trials. Besides, from 3 months to 6 months, the sham injection number of the conservative group dropped or even disappeared. Pain scores were similar in the PVP and sham injection groups from 2 weeks to 6 months. There are several possible explanations for this observation. First, the local anesthesia provided as part of the sham procedure might afford a degree of medium- to long-term analgesia; local infiltration with bupivacaine may act as a nerve block to relieve pain. Second, the relatively small sample size of these 2 studies $(n=209)$ might have led to false negative differences between the PVP and sham injection groups $(15,18)$. Third, the sham procedure might have a placebo effect. Finally, but the most importantly, PVP may also afford analgesia by means of a placebo response.

There were many publications which have reported the placebo response (24-29). The present evidence illustrated that the placebo effect depended on a variety of neurochemical and neurophysiological mechanisms, which were measurable and modifiable. But the placebo response was inexorably tied to the context of treatment. All medical treatments took place in a particular context, which included the therapist's attitude, psychosocial factors affecting the therapeutic relationship, and the patient's mindset. Therapeutic efficacy at least in part was attributable to the concordance between the proposed treatment and the patient's belief system. It was this fraction of the thera-
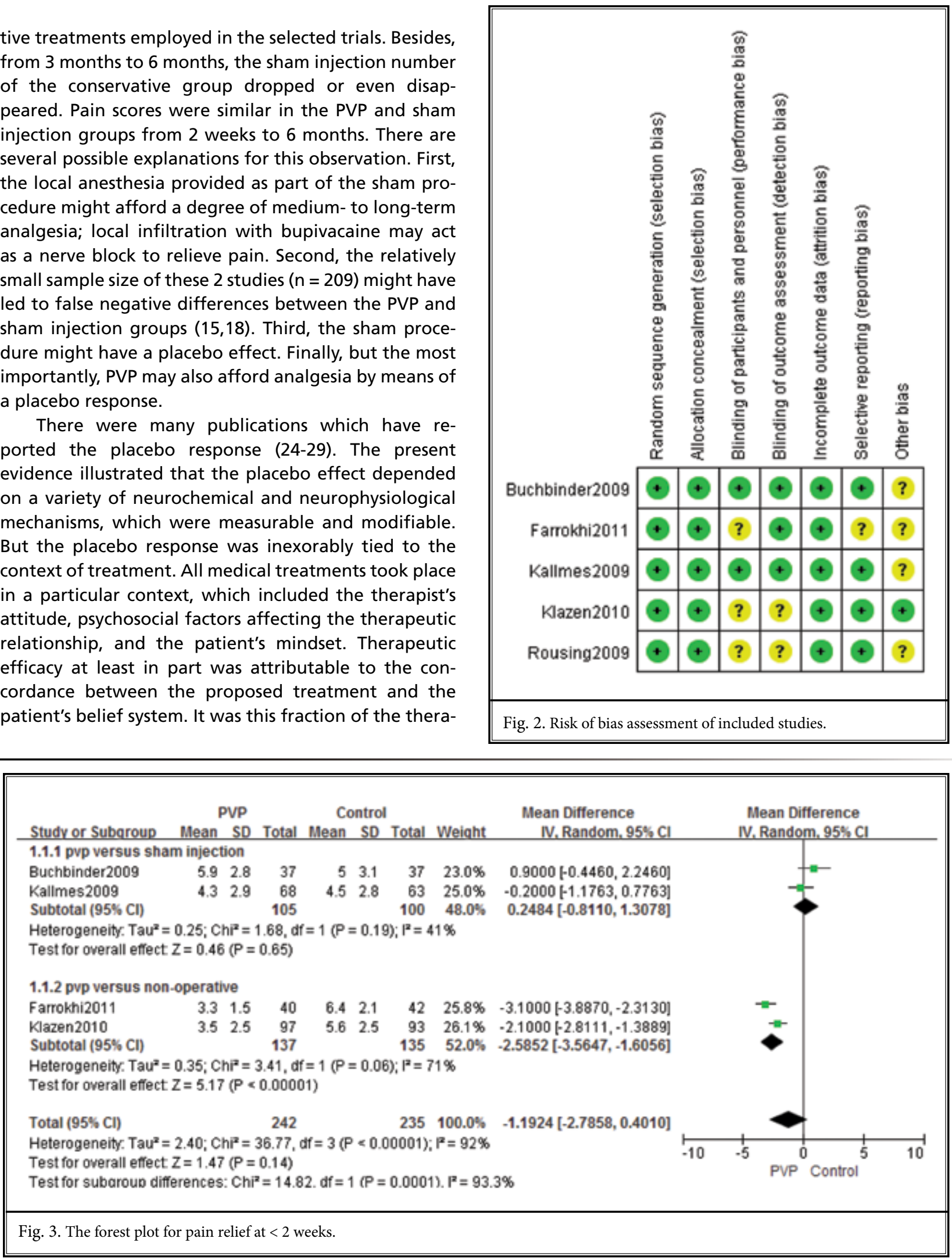

www.painphysicianjournal.com 


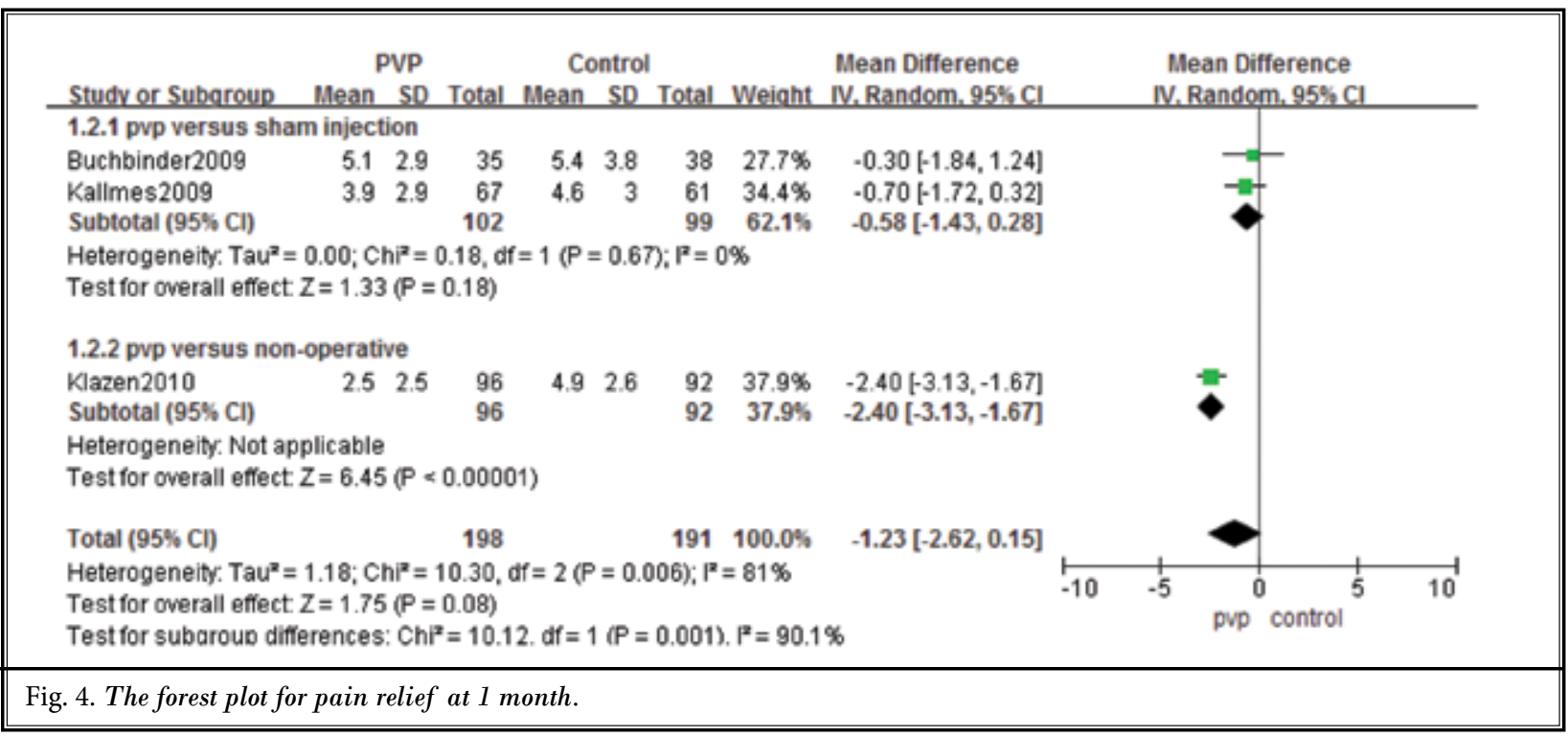

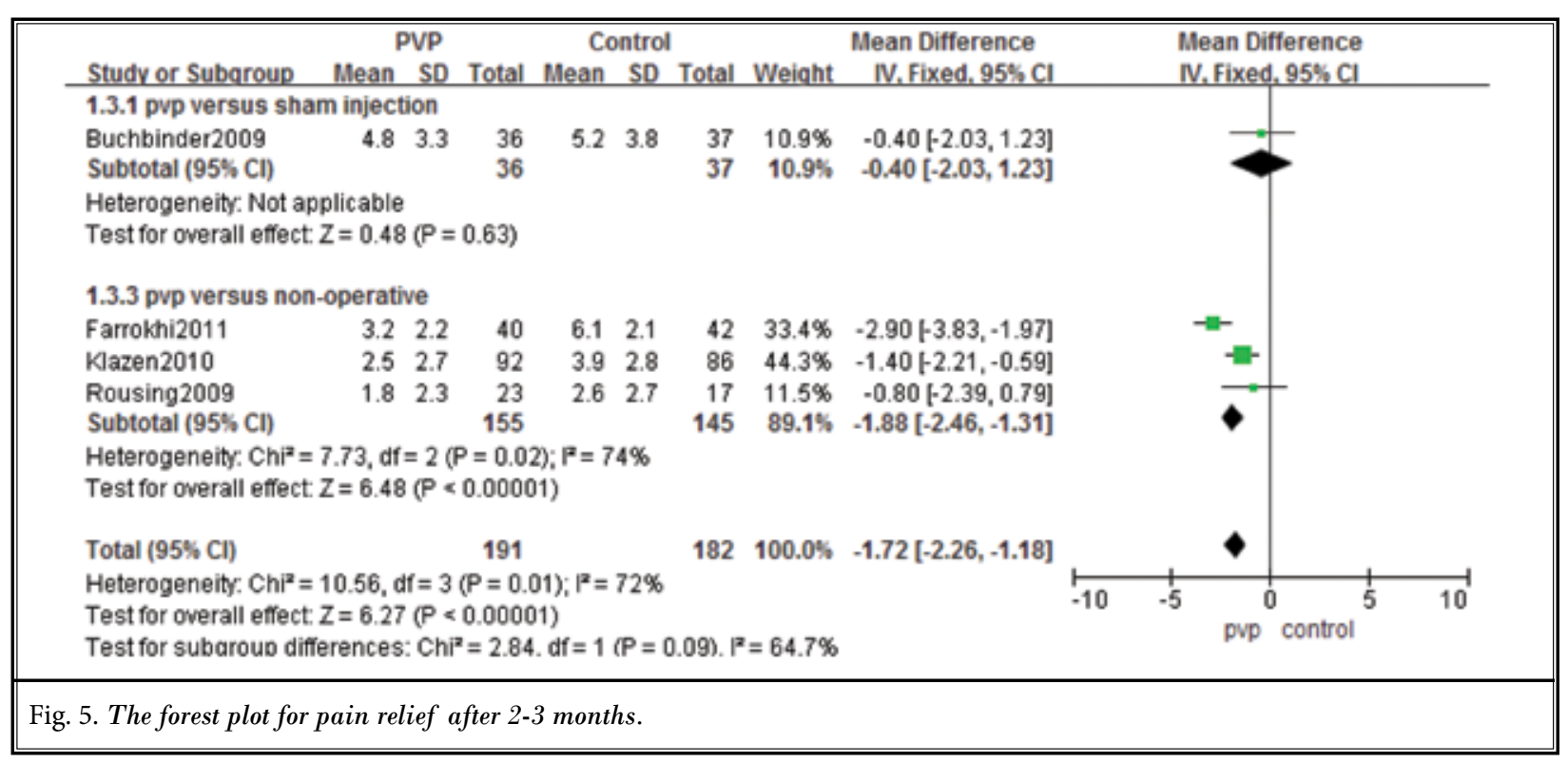

peutic response that was commonly called the placebo effect. More formally, the placebo effect was defined as that part of the therapeutic response which was not attributable to the properties of active ingredients (24). Spontaneous improvement and effect of placebo contributed importantly to the observed treatment effect in actively treated patients, but the relative importance of these factors differed according to clinical condition and intervention (29). However, creative experimental efforts were still needed to assess rigorously the clinical significance of placebo interventions and investigate the component elements that may contributed to therapeutic benefit (28).

Conservative treatments are continuously used to treat OVCF in clinical practice. Conservative treatments include bed rest, optimum pain treatment, optimal medical therapy, and placebo treatment, et al. We think that the pain relief in the placebo treatment is different from the natural course of pain with OVCF to a certain extent. When the placebo treatment is 


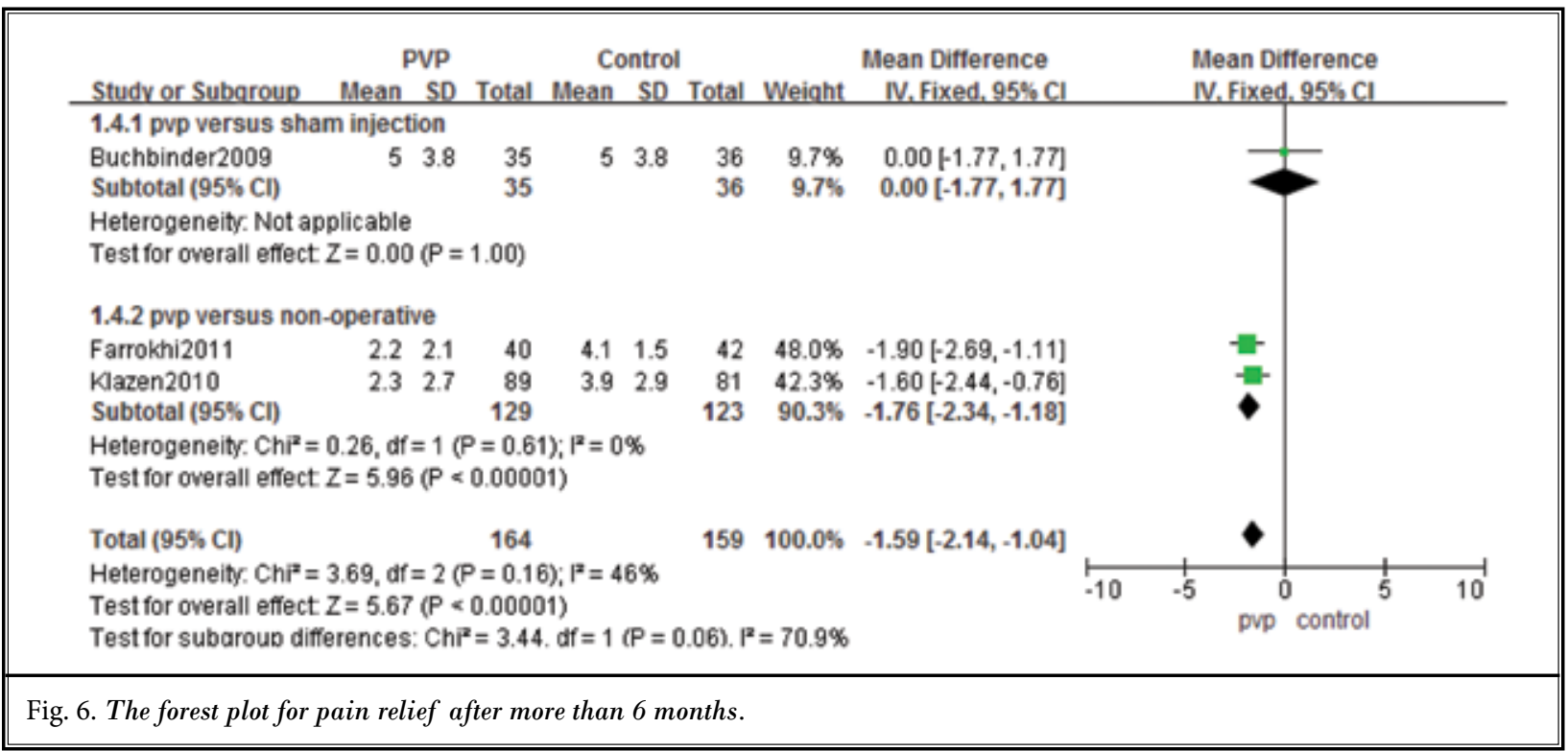

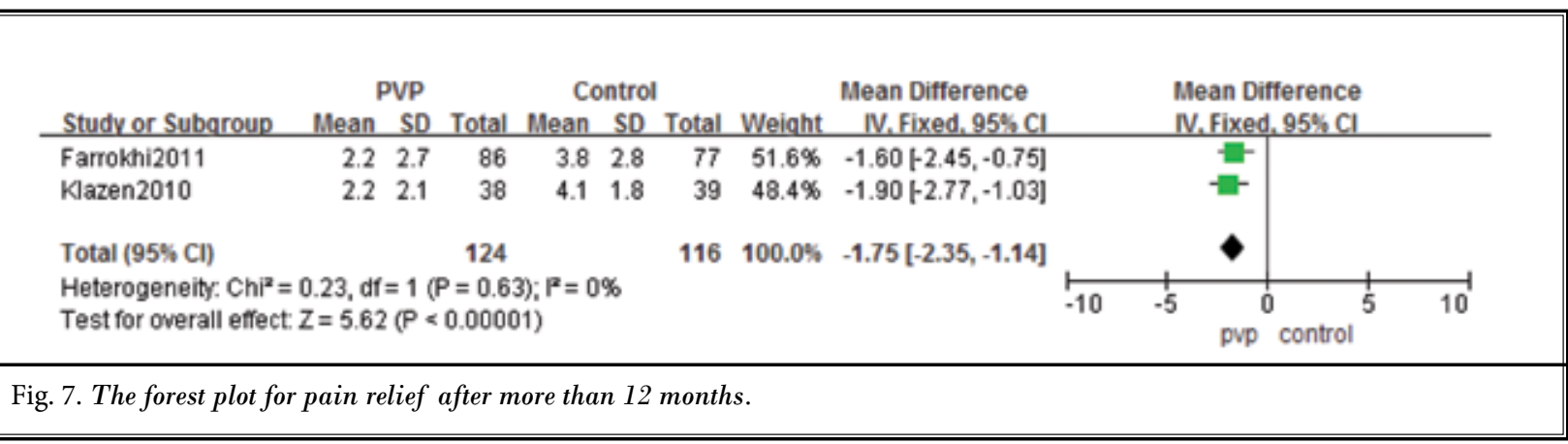

invasive, the remarkable pain relief could be achieved in the short-term. There may be several reasons to explain the placebo effect, such as narcotic effects, psychological effects, and neural excitatory effects (30-32). However, in the long-term, the pain relief with the placebo treatment is similar to the natural course of pain with OVCF. We will pay close attention to this issue in future.

After analysis of the data yielded from the randomized controlled research into PVP, our opinion is that PVP can reduce the amount of pain after OVCF, but that there may be an element of placebo in this benefit. The trials published in the New England Journal of Medicine were well designed $(15,18)$, the implementation standards foresightedness findings extrapolation is high, thus the quality of evidence yielded from these reports is high. However, even these studies were relatively small, and larger studies are needed in broader patient groups and populations. If these should arrive at the same conclusion, it would imply that previous positive results are the consequence of inadequately designed studies or statistical quirks, and the dispute about the utility of PVP would be resolved.

Although PVP is generally considered to be a safe procedure, rare but serious complications may occur. The most frequent is cement leak, which may lead to spinal cord injury and varying degrees of motor or sensory nerve dysfunction (33-35). Other serious complications that have been reported include cement pulmonary embolism $(36,37)$ and osteomyelitis in a patient with established infection (38). Since the value of PVP in the management of OVCF is still not clear, conservative treatments are still warranted and are generally still employed before the decision to undertake PVP is made. Conservative treatments might be less expensive and have fewer and less serious associated complications. 
In addition, kyphoplasty is utilized commonly in clinical practice to treat OVCF as another surgical approach. However, there is also a dispute in the treatment of OVCF with kyphoplasty. A publication by Lee et al (39) reported that both kyphoplasty and conservative treatment of OVCF showed successful clinical results at the end of the one-year follow-up period and kyphoplasty showed better outcomes in the first month only. Given these results, prompt kyphoplasty should not be indicated in the case of a patient with OVCF that has no risk factors for failure with conservative treatment.

Several systematic reviews and meta-analyses have examined the utility of vertebroplasty and kyphoplasty compared with non-operative treatment (40-42). The emphasis and conclusions they drew are somewhat different from ours. Anderson and colleagues (43) conducted a systematic review of studies comparing nonoperative treatment with cement augmentation using a similar methodology to ours, and reported that pain improvement was significantly greater in the cement group at all time points from 3 to 12 months although the magnitude of improvement diminished over time. Importantly, however, data from studies of percutaneous kyphoplasty (PKP) were included and there is no conclusive proof that PKP is as effective as PVP (20). Anderson et al (43) concluded that cement augmentation of OVCF conveyed a therapeutic benefit, but did not consider the placebo effect or analyze subgroups. A systematic review of non-randomized controlled research has also been conducted (44), with a different emphasis and methodology to our study. Other studies have included assessments of complications $(41,42,45)$; however, we chose to focus on pain relief as the most important outcome measure.

\section{Limitations}

One limitation of our study is that there were few sources from which to extract abstracted data or published studies. There were only 5 randomized controlled trials that met our criteria. Although the risk of publication bias exists in any meta-analysis, whether based on individual patient data or not, we feel that this was not an important aspect of our study as both positive and negative trials were included. Obvious confounding variables are differences in inclusion and exclusion criteria, treatment modalities employed, and endpoints. To account for this heterogeneity a random effects model was chosen. Another limitation was that the treatments administered to patients in the comparison groups were non-uniform and varied widely; some were conservative but 2 used sham surgery controls $(15,18)$.

\section{Conclusion}

In conclusion, our analysis demonstrates that there were differences in pain relief experienced by patients undergoing PVP and those managed conservatively at some time points. However, we are still not able to state which is the optimal approach and superior treatment for OVCF. Large, randomized, placebo-controlled clinical trials that compare conservative treatment with vertebroplasty over several years are needed to provide a definitive answer to the question of how best to treat OVCF.

\section{Acknowledgments}

This study was supported by the Natural Science Fundation of China (81102604). This study was also designed by Dr Yongjun Wang.

\section{References}

1. Bliuc D, Nguyen ND, Milch VE, Nguyen TV, Eisman JA, Center JR. Mortality risk associated with low-trauma osteoporotic fracture and subsequent fracture in men and women. JAMA 2009; 301:513-521.

2. Harris ST, Watts NB, Genant HK, McKeever $C D$, Hangartner T, Keller M, Chesnut $\mathrm{CH}$ 3rd, Brown J, Eriksen EF, Hoseyni MS, Axelrod DW, Miller PD. Effects of risedronate treatment on vertebral and nonvertebral fractures in women with postmenopausal osteoporosis: A randomized controlled trial. Vertebral Efficacy With Risedronate Therapy (VERT)
Study Group. JAMA 1999; 282:1344-1352.

3. Klazen CA, Lohle PN, de Vries J, Jansen $\mathrm{FH}$, Tielbeek AV, Blonk MC, Venmans A, van Rooij WJ, Schoemaker MC, Juttmann JR, Lo TH, Verhaar HJ, van der Graaf $Y$, van Everdingen KJ, Muller AF, Elgersma OE, Halkema DR, Fransen $\mathrm{H}$, Janssens X, Buskens E, Mali WP. Vertebroplasty versus conservative treatment in acute osteoporotic vertebral compression fractures (Vertos II): An openlabel randomised trial. Lancet 2010; 376:1085-1092.

4. Gill JB, Kuper M, Chin PC, Zhang Y,
Schutt R, Jr. Comparing pain reduction following kyphoplasty and vertebroplasty for osteoporotic vertebral compression fractures. Pain Physician 2007; 10:583-590.

5. Gray DT, Hollingworth W, Onwudiwe N, Jarvik JG. Costs and state-specific rates of thoracic and lumbar vertebroplasty, 2001-2005. Spine (Phila Pa 1976) 2008; 33:1905-1912.

6. Hao J, Hu Z. Percutaneous cement vertebroplasty in the treatment of symptomatic vertebral hemangiomas. Pain Physician 2012; 15:43-49. 
7. Sonmez E, Yilmaz C, Caner H. Development of lumbar disc herniation following percutaneous vertebroplasty. Spine (Phila Pa 1976) 2010; 35:E93-95.

8. Anselmetti GC, Manca A, Hirsch J, Montemurro F, Isaia G, Osella G, Chiara G, lussich G, Debernardi F, Regge D. Percutaneous vertebroplasty in osteoporotic patients: An institutional experience of 1,634 patients with long-term follow-up. J Vasc Interv Radiol 2011; 22:1714-1720.

9. Hiwatashi A, Moritani T, Numaguchi $\mathrm{Y}$, Westesson PL. Increase in vertebral body height after vertebroplasty. AJNR Am J Neuroradiol 2003; 24:185-189.

10. Deramond H, Mathis JM. Vertebroplasty in osteoporosis. Semin Musculoskelet Radiol 2002; 6:263-268.

11. Kim DH, Vaccaro AR. Osteoporotic compression fractures of the spine; current options and considerations for treatment. Spine ] 2006; 6:479-487.

12. Rousing $R$, Andersen $M O$, Jespersen SM, Thomsen K, Lauritsen J. Percutaneous vertebroplasty compared to conservative treatment in patients with painful acute or subacute osteoporotic vertebral fractures: Three-months follow-up in a clinical randomized study. Spine (Phila Pa 1976) 2009; 34:1349-1354.

13. Biagi JJ, Raphael MJ, Mackillop WJ, Kong W, King WD, Booth CM. Association between time to initiation of adjuvant chemotherapy and survival in colorectal cancer: A systematic review and metaanalysis. JAMA 2011; 305:2335-2342.

14. Chen Z, King W, Pearcey R, Kerba $M$, Mackillop WJ. The relationship between waiting time for radiotherapy and clinical outcomes: a systematic review of the literature. Radiother Oncol 2008; 87:3-16.

15. Buchbinder R, Osborne RH, Ebeling PR, Wark JD, Mitchell P, Wriedt C, Graves S, Staples MP, Murphy B. A randomized trial of vertebroplasty for painful osteoporotic vertebral fractures. $N$ Engl J Med 2009; 361:557-568.

16. Abrams KR, Gillies CL, Lambert PC. Meta-analysis of heterogeneously reported trials assessing change from baseline. Stat Med 2005; 24:3823-3844.

17. Farrokhi MR, Alibai E, Maghami Z. Randomized controlled trial of percutaneous vertebroplasty versus optimal medical management for the relief of pain and disability in acute osteoporotic vertebral compression fractures. J Neurosurg Spine 2011; 14:561-569.

18. Kallmes DF, Comstock BA, Heagerty
PJ, Turner JA, Wilson DJ, Diamond TH, Edwards R, Gray LA, Stout L, Owen S, Hollingworth W, Ghdoke B, AnnesleyWilliams DJ, Ralston SH, Jarvik JG. A randomized trial of vertebroplasty for osteoporotic spinal fractures. N Engl J Med 2009; 361:569-579.

19. Voormolen $\mathrm{MH}$, Mali WP, Lohle PN, Fransen $H$, Lampmann LE, van der Graaf Y, Juttmann JR, Jansssens X, Verhaar HJ. Percutaneous vertebroplasty compared with optimal pain medication treatment: Short-term clinical outcome of patients with subacute or chronic painful osteoporotic vertebral compression fractures. The VERTOS study. AJNR $A m$ ] Neuroradiol 2007; 28:555-560.

20. Wardlaw D, Cummings SR, Van Meirhaeghe J, Bastian L, Tillman JB, Ranstam J, Eastell R, Shabe P, Talmadge K, Boonen S. Efficacy and safety of balloon kyphoplasty compared with nonsurgical care for vertebral compression fracture (FREE): A randomised controlled trial. Lancet 2009; 373:1016-1024.

21. Diamond TH, Champion B, Clark WA. Management of acute osteoporotic vertebral fractures: A nonrandomized trial comparing percutaneous vertebroplasty with conservative therapy. Am J Med 2003; 114:257-265.

22. Wang HK, Lu K, Liang CL, Weng $\mathrm{HC}$, Wang KW, Tsai YD, Hsieh CH, Liliang PC. Comparing clinical outcomes following percutaneous vertebroplasty with conservative therapy for acute osteoporotic vertebral compression fractures. Pain Med 2010; 11:1659-1665.

23. Alvarez L, Alcaraz $M$, Perez-Higueras A, Granizo J, de Miguel I, Rossi RE, Quinones D. Percutaneous vertebroplasty: Functional improvement in patients with osteoporotic compression fractures. Spine (Phila Pa 1976) 2006; 31:1113-1118.

24. Manchikanti L, Giordano J, Fellows B, Hirsch JA. Placebo and nocebo in interventional pain management: $A$ friend or a foe--or simply foes? Pain Physician 2011; 14:E157-175.

25. Hrobjartsson A, Kaptchuk TJ, Miller FG. Placebo effect studies are susceptible to response bias and to other types of biases. J Clin Epidemiol 2011; 64:1223-1229.

26. Louhiala $P$. The ethics of the placebo in clinical practice revisited. Journal of Medical Ethics 2009; 35:407-409.

27. Blease $C$. The principle of parity: The 'placebo effect' and physician communication. Journal of Medical Ethics 2011; 38:199-203.
28. Hróbjartsson A, Kaptchuk TJ, Miller FG. Placebo effect studies are susceptible to response bias and to other types of biases. Journal of Clinical Epidemiology 2011; 64:1223-1229.

29. Krogsbøll L, Hróbjartsson A, Gøtzsche PC. Spontaneous improvement in randomised clinical trials: meta-analysis of three-armed trials comparing no treatment, placebo and active intervention. BMC Medical Research Methodology 2009; 9:1.

30. Moerman DE, Jonas WB. Deconstructing the placebo effect and finding the meaning response. Ann Intern Med 2002; 136:471-476.

31. Jarvik JG, Deyo RA. Cementing the evidence: time for a randomized trial of vertebroplasty. AJNR Am J Neuroradiol 2000; 21:1373-1374.

32. Flum DR. Interpreting surgical trials with subjective outcomes: Avoiding UnSPORTsmanlike conduct. JAMA 2006; 296:2483-2485.

33. Chen YJ, Tan TS, Chen WH, Chen CC, Lee TS. Intradural cement leakage: A devastatingly rare complication of vertebroplasty. Spine (Phila Pa 1976) 2006; 31:E379-382.

34. Hochegger M, Radl R, Leithner A, Windhager R. Spinal canal stenosis after vertebroplasty. Clin Radiol 2005; 60:397-400.

35. Lee BJ, Lee SR, Yoo TY. Paraplegia as a complication of percutaneous vertebroplasty with polymethylmethacrylate: A case report. Spine (Phila Pa 1976) 2002; 27:E419-422.

36. Stricker K, Orler R, Yen K, Takala J, Luginbuhl M. Severe hypercapnia due to pulmonary embolism of polymethylmethacrylate during vertebroplasty. Anesth Analg 2004; 98:1184-1186, table of contents.

37. Yoo KY, Jeong SW, Yoon W, Lee J. Acute respiratory distress syndrome associated with pulmonary cement embolism following percutaneous vertebroplasty with polymethylmethacrylate. Spine (Phila Pa 1976) 2004; 29:E294-297.

38. Walker DH, Mummaneni P, Rodts GE, Jr. Infected vertebroplasty. Report of two cases and review of the literature. Neurosurg Focus 2004; 17:E6.

39. Lee HM, Park SY, Lee SH, Suh SW, Hong JY. Comparative analysis of clinical outcomes in patients with osteoporotic vertebral compression fractures (OVCFs): Conservative treatment versus balloon kyphoplasty. The Spine Journal 2012; 12:998-1005. 
40. Ma X-L, Xing D, Ma J-X, Xu W-G, Wang $J$, Chen Y. Balloon kyphoplasty versus percutaneous vertebroplasty in treating osteoporotic vertebral compression fracture: grading the evidence through a systematic review and metaanalysis. European Spine Journal 2012; 21:1844-1859.

41. Zhang Z, Fan J, Ding Q, Wu M, Yin G. Risk factors for new osteoporotic vertebral compression fractures after vertebroplasty. J Spin Dis Tech 2013;
26:E150-E157.

42. Felder-Puig R, Piso B, Guba B, Gartlehner G. Kyphoplastie und Vertebroplastie bei osteoporotischen Wirbelkörperkompressionsfrakturen. Der Orthopäde 2009; 38:606-615.

43. Anderson PA, Froyshteter AB, Tontz WL. Meta-analysis of vertebral augmentation compared to conservative treatment for osteoporotic spinal fractures. Journal of Bone and Mineral Research 2012; n/a-n/a.
44. Shi M-M, Cai X-Z, Lin T, Wang W, Yan S-G. Is there really no benefit of vertebroplasty for osteoporotic vertebral fractures? A meta-analysis. Clin Orthop Relat Res 2012; 470:2785-2799.

45. Zou J, Mei X, Zhu X, Shi Q, Yang H. The long-term incidence of subsequent vertebral body fracture after vertebral augmentation therapy: a systemic review and meta-analysis. Pain Physician 2012; $15: E_{515-522 .}$ 